\title{
Assessment of risk factors for hypertension in Dormaa municipality in Ghana using the World Health Organization STEPS approach
}

Fidelis Atibila1*, Ellis Owusu Dabo², James Avoka Asamani³, Charles Ampong Adjei Francis Abande Akugri ${ }^{5}$, Priscilla Adumoah Attafuah ${ }^{4}$

'Department of Nursing, Valley View University, Adentan, Accra, Ghana, ${ }^{2}$ Kumasi Centre for Collaborative Research, Kumasi, Ghana, ${ }^{3}$ Department of Planning and Monitoring, Ghana Health Service, Accra, Ghana, ${ }^{4}$ Department of Nursing, Valley View University, Adentan, Accra, Ghana, ${ }^{5}$ Department of Nursing, Nsawam Government Hospital, Nsawam, Ghana

\section{ABSTRACT}

Intruduction: Hypertension (HPT) is an important public health challenge worldwide and is the single most important risk factor for cardiovascular disease. As life expectancy rates improve in Ghana and the prevalence of risk factors increase, the burden of non-communicable diseases such as HPT is also expected to increase. However, little is known about the specific factors that predispose of Ghanaians to greater risk of HPT.

Methods: A cross-sectional study was conducted in the Dormaa Municipality in Ghana using the World Health Organization STEPwise approach to investigate risk factors for HPT. Study participants were recruited by probability proportional sampling techniques. In all, 202 males and 198 females participated in this study.

Results: The mean age of the participants was 50.06 years (95\% confidence interval [CI]: 48.46-51.66). In all, $40 \%$ of all participants in this study had an elevated blood pressure (BP) (BP $\geq 140 / 90 \mathrm{mmHg}$ ). Further, the rate of isolated systolic HPT was $11.2 \%$ among the study population $(12.9 \%$ in males and $9.6 \%$ in females). Risk factors as measured in the population were advancing age $>45$ years (odds ratio $[\mathrm{OR}]=2.745$, $\mathrm{Cl} 1.20-6.30, p=0.017)$, gender (44.6\% males versus $35.4 \%$ females with elevated $\mathrm{BP}$, male $\mathrm{OR}=0.492, \mathrm{Cl}$ $0.28-0.86, p=0.012)$, and tobacco use $(\mathrm{OR}=2.66, \mathrm{Cl} 1.41-5.04, p=0.003)$. Males reported higher mean portions of fruits $(p=0.036)$ and vegetable servings than females $(p=0.009)$ and spent more time each day on physical activities compared to females $(p=0.000)$.

Conclusion: The results of the present study provide useful data on HPT prevalence and associated risk factors in the Dormaa Municipality and the Brong-Ahafo Region of Ghana. To be able to control HPT in the municipality, health practitioners and policymakers should focus on these modifiable risk factors.

Key words: Hypertension; risk factors for hypertension; STEPS approach

\footnotetext{
${ }^{*}$ Corresponding author: Fidelis Atibila, MPH, BSc, Dip., RN. Valley View University, Box AF 595 Adentan, Accra. E-mail: fidelisatibila2013@gmail.com
}

Submitted: 15 September 2018/Accepted: 12 November 2018

DOI: https://doi.org/10.17532/jhsci.2018.281

UNIVERSITY OF SARAJEVO FACULTY OF HEALTH STUDIES

\section{INTRODUCTION}

Hypertension (HPT) remains an important public health concern which according to the World Health Organization (WHO) (1), contributes to about $45 \%$ of deaths attributable to heart diseases 
and $51 \%$ of stroke globally. Many low- and middle-income countries have entered, or are entering, what has been termed the "epidemiologic transition" (2) in which the burden of communicable diseases is still high amidst an upsurge of chronic non-communicable diseases (NCDs). Furthermore, it is well documented that three-quarters of people with HPT reside in developing countries, especially Africa where there are limited health resources, low level of awareness of HPT, and poor blood pressure (BP) control (1). Compared with a prevalence rate of about $1.8 \%$ reported in the 1940 s (3), it has, surprisingly, increased several folds and is predicted to grow by more than 500 million by 2025 (4). Many factors are reported to increase the risk and complications associated with HPT including tobacco use, excessive alcohol consumption, unhealthy dietary behavior, and physical inactivity which ultimately have adverse effects on longevity and quality of life (5).

In Ghana, HPT has gradually and progressively become an important public health challenge, even in the poorest rural communities. For instance, a survey conducted several decades ago in a village found that only $5.5 \%$ of the village inhabitants had cardiovascular diseases (6). In contrast, one community-based survey found that the prevalence of HPT was about $29.4 \%$, but $34 \%$ of the sufferers were unaware while only $28 \%$ were receiving treatment among whom only $6.2 \%$ had well-controlled BP levels lower that than $140 / 90 \mathrm{mmHg}$ (7). Other studies have also reported a prevalence rate of $27.4 \%$ (95\% confidence interval [CI] 24.7-30.1\%) (8). Institutional clinical data have also shown that the number of reported new cases of HPT in public health facilities in Ghana increased more than ten-fold from 49,087 in 1988 to 505,180 in 2007 (9). Furthermore, during the same period, HPT relative to the total reported outpatient diseases increased from $1.7 \%$ to $4.0 \%$ in all ages (9). The aforesaid corroborates some reviews of population surveys of HPT in Ghana published between 1970 and 2009 which revealed that the prevalence rate of HPT was between 19\% in rural areas and $55 \%$ in urban areas $(10,11)$. Worryingly, however, one of the reviews (10) also revealed that the rate of control of HPT very low, ranging from $1.7 \%$ to $12.7 \%$. The poor control of HPT in Ghana has also been attributed to medication noncompliance underpinned by the high cost of treatment (12). Thus,
HPT has not only become a public health threat but also poses a risk of catastrophic health expenditure.

Although clinical, social, and economic burden of HPT is widely acknowledged (13), most of the research efforts have rather focused on determining the prevalence rate and awareness creation (7,14-17) and systematic reviews of same $(10,11)$ to the neglect of the risk factors for HPT which are the starting point for prevention and control efforts. This study, therefore, sought to empirically examine the risk factors associated with HPT based on the WHO STEPwise approach. To the best of our knowledge, it appears that this is the first attempt of examining the risk factors for HPT in a Ghanaian population using this approach.

\section{METHODS}

\section{Study design}

A cross-sectional study was used to determine the risk factors associated with HPT in the Dormaa Municipality of the Brong-Ahafo Region, Ghana. The study was a community-based cross-sectional house-to-house survey aimed at ascertaining the prevalence of HPT in the municipality as well as identifying related risk factors.

\section{Study area}

The study was carried out in the Dormaa Municipality, which is located in the western part of the Brong-Ahafo region of Ghana. It has a total land area of $1210.8 \mathrm{~km}^{2}$ and an estimated population of 159,789 (78,270 males and 81,519 females) (18). A total of 10,936 number of households are in the municipality with an average household size of 5.2 persons (18).

\section{Population, sample size, and sampling technique}

The study population comprised individuals aged 25 years or older living in rural and urban areas of the Dormaa Municipality in the Brong-Ahafo Region. It, however, excluded persons who were known to have a severe mental illness, as they could not willfully consent to be part of the study.

The sample size was determined using Cochran's maximum proportions formula (19). The sample that was deemed sufficiently representative of the entire population was obtained conservatively by 
by assuming that the rate of HPT in the municipality is $50 \%$. Based on the published population of 159,578 inhabitants in the Dormaa municipality, a minimum sample size of 383 was calculated to be sufficient (20). However, to cater for possible non-response, the sample size was adjusted to 400 .

The participants were randomly selected using a multistage cluster sampling technique. The municipality was divided into five clusters based on the pattern of settlement. Each cluster was allotted a quota of the sample proportional to their population size. The database of all households in the municipality was obtained from the Volta River Authority which has the most up to date contact information of households for the purpose of distributing household bills in the study setting. After obtaining the list of households and their contact details, a random selection of households in all the clusters was made. The selected households were then contacted through telephone to obtain their consent or otherwise to be part of the study. Households that consented to be part of the study were visited by the researchers, and all members of the household who met the inclusion criteria and individually consented were recruited.

\section{Instruments for data collection}

The WHO STEPwise instrument for evaluating risk factors for NCDs (21) was used to collect the data. The WHO STEPS tool has been used for risk factor surveillance in a number of countries in sub-Saharan Africa (22). This approach consists of collecting information using questionnaires (Step 1), physical measurements (Step 2), and taking blood samples for biomedical assessment (Step 3), for the assessment of risk factors. In this study, however, only the first and second steps were carried out due to logistical constraints. Measurements were done using calibrated and standard instruments. We measured height with participants standing without shoes using a standard metal ruler. Weight was measured using calibrated digital scales. All participants wore light clothes for weighing. Waist circumference was measured midway between the lower rib margin and iliac crest to the nearest $0.5 \mathrm{~cm}$. BP was measured using a digital BP apparatus. BP measurement and definition of HPT was based on the WHO guidelines. Physical activity was measured using questions on four different aspects, physical activity at the workplace, physical activity during recreation time, physical activity while traveling, and physical resting time. To define a combined risk factor index, five components were considered: Being a current daily smoker; five servings of fruits and vegetables per day; low level of activity (600 metabolic energy time in minutes); body mass index (BMI) $\geq 25 \mathrm{~kg} / \mathrm{m}^{2}$; and raised BP (systolic BP $[\mathrm{SBP}] \geq 140$ and/or diastolic BP $[\mathrm{DBP}] \geq 90 \mathrm{mmHg}$ ). Participants who lacked any of these were classified as low risk and those having at least three of the above-mentioned risk factors were considered as a high risk of NCDs. For the definition of abdominal obesity, the cutoff points of $102 \mathrm{~cm}$ in men and $88 \mathrm{~cm}$ in women were used according to the WHO guidelines.

The physical examinations and anthropometric measurements were carried out by a team of trained nurses and health professionals. The research team visited households according to the previously arranged appointments. Before the interviews by the team, appointments were made at least 1 day before and preferably during evenings when most people are at home.

\section{Data analysis}

The data obtained through the questionnaires were checked for accuracy and entered immediately into the computer using Statistical Package for the Social Sciences version 21 and Microsoft ${ }^{\oplus}$ Excel $^{\oplus}$ software. Both descriptive and inferential statistical analysis was performed. Differences between proportions were tested using Chi-square test.

\section{Ethical considerations}

Ethical clearance for the commencement of the study was obtained from the Committee on Human Research Publication and Ethics (CHRPE), Kwame Nkrumah University of Science and Technology, School of Medical Sciences, and the Municipal Director of Health Services in the study area. In line with ethical modalities, study participants were adequately informed of the purpose, nature, procedures, risks, and hazards of the study and their written consent was also sought. Emphasis was placed on anonymity, confidentiality, and the freedom to decline to participate at any time without penalty. 


\section{RESULTS}

\section{Sociodemographic characteristics of participants}

The sociodemographic characteristics of the study population as shown in Table 1 indicates that out of a total of 400 respondents who participated in this study, 202 (50.5\%) were males and 198 (49.5\%) were females. The mean age of the participants was 50.06 years (95\% CI: 48.46-51.66). The median age ranged from 45 to 54 years. Illiteracy was reported to be $37.5 \%$ of study participants with the majority of them being females. Most of the study participants $(32.25 \%)$ had middle/Junior high as their highest level of educational attainment and had been in formal education for at most 9 years. The data suggest that males in the study population were more likely to be highly educated than females $(p=0.010)$. In all, only $6.75 \%$ of participants

TABLE 1. Sociodemographic characteristics of the study population stratified by gender $n(\%)$

\begin{tabular}{|c|c|c|c|c|}
\hline Parameter & Total & Male & Female & $p$ value \\
\hline \multicolumn{5}{|l|}{ Age group } \\
\hline $25-34$ & $77(19.25)$ & $39(9.75)$ & $38(9.50)$ & \multirow[t]{6}{*}{0.987} \\
\hline $35-44$ & $85(21.25)$ & $42(10.50)$ & $43(10.75)$ & \\
\hline $45-54$ & $79(19.75)$ & $41(10.25)$ & $38(9.50)$ & \\
\hline $55-64$ & $80(20.00)$ & $39(9.75)$ & $41(10.25)$ & \\
\hline$\geq 65$ & $79(19.75)$ & $41(10.25)$ & $38(9.50)$ & \\
\hline Total & $400(100)$ & $202(50.5)$ & $198(49.5)$ & \\
\hline \multicolumn{5}{|l|}{ Education } \\
\hline No formal school & $150(37.5)$ & $63(15.75)$ & $87(21.75)$ & \multirow[t]{8}{*}{0.010} \\
\hline Less than primary school & $15(3.75)$ & $6(1.50)$ & $9(2.25)$ & \\
\hline Completed prim school & $31(7.75)$ & $15(3.75)$ & $16(4.00)$ & \\
\hline JSS/Middle school & $129(32.25)$ & $66(16.50)$ & $63(15.75)$ & \\
\hline SHS/High school & $45(11.25)$ & $28(7.00)$ & $17(4.25)$ & \\
\hline College/University & $27(6.75)$ & $21(5.25)$ & $6(1.50)$ & \\
\hline Postgraduate degree & $3(0.75)$ & $3(0.75)$ & $0(0.00)$ & \\
\hline Total & $400(100)$ & $202(50.5)$ & $198(49.5)$ & \\
\hline \multicolumn{5}{|l|}{ Ethnicity } \\
\hline Akan & $330(82.50)$ & $132(33)$ & $198(49.5)$ & \multirow[t]{5}{*}{0.000} \\
\hline $\mathrm{Ga}$ & $9(2.25)$ & $9(2.25)$ & $0(0.00)$ & \\
\hline Ewe & $12(3.00)$ & $12(3.00)$ & $0(0.00)$ & \\
\hline Mole-Dagbani & $49(12.25)$ & $49(12.25)$ & $0(0.00)$ & \\
\hline Total & $400(100)$ & $202(50.5)$ & $198(49.5)$ & \\
\hline \multicolumn{5}{|l|}{ Work status } \\
\hline Government employee & $60(15.00)$ & $35(8.75)$ & $25(6.25)$ & \multirow[t]{6}{*}{0.095} \\
\hline Non-Government employee & $246(61.50)$ & $126(31.50)$ & $120(30.00)$ & \\
\hline Self-employed & $24(6.00)$ & $8(2.00)$ & $16(4.00)$ & \\
\hline Volunteer & $26(6.50)$ & $13(3.25)$ & $13(3.25)$ & \\
\hline Student & $44(11.00)$ & $20(5.00)$ & $24(6.00)$ & \\
\hline Total & $400(100)$ & $202(50.5)$ & $198(49.5)$ & \\
\hline \multicolumn{5}{|l|}{ Marital status } \\
\hline Never married & $99(24.75)$ & $48(12.00)$ & $51(12.75)$ & \multirow[t]{5}{*}{0.346} \\
\hline Currently married & $126(31.50)$ & $58(14.50)$ & $68(17.00)$ & \\
\hline Separated & $160(40.00)$ & $86(21.50)$ & $74(18.50)$ & \\
\hline Widowed & $15(3.75)$ & $10(2.50)$ & $5(1.25)$ & \\
\hline Total & $400(100)$ & $202(50.5)$ & $198(49.5)$ & \\
\hline
\end{tabular}


TABLE 2. Summary of results from step 1 WHO STEPS approach studying risk factors of NCDs $n(\%)$

\begin{tabular}{lccccc}
\hline Parameter & Male & Female & Total & $95 \% \mathrm{Cl}$ & $p$ value \\
\hline Step 1 Tobacco use & & & & & \\
$\quad$ Percentage who currently smoke tobacco daily & 22.4 & 1.5 & 12.0 & & 0.000 \\
$\quad$ Step 1 Fruit and vegetable consumption (in a typical week) & & & & & \\
$\quad$ Mean number of servings of fruit consumed per day & 1.75 & 1.40 & 1.59 & $1.41-1.74$ & 0.036 \\
$\quad$ Mean number of servings of vegetables consumed per day & 3.38 & 2.30 & 2.85 & $2.45-3.26$ & 0.009 \\
$\quad$ Percentage who ate $\geq 5$ combined servings of fruit and vegetables per day & 36.1 & 17.2 & 26.8 & & 0.000 \\
Step 1 Physical activity & & & & & \\
$\quad$ Percentage with low levels of activity (defined as <600 MET-minutes/week) & 29.7 & 46.2 & 37.3 & & 0.004 \\
$\quad$ Median time spent in physical activity per day (hours) & 3.56 & 2.22 & 2.90 & $2.50-3.29$ & 0.000 \\
\hline
\end{tabular}

MET: Metabolic energy, Cl: Confidence interval, NCDs: Non-communicable diseases

TABLE 3. Summary of results from step 2 WHO STEPS approach studying risk factors of NCDs (\%)

\begin{tabular}{|c|c|c|c|c|c|}
\hline Parameter & Male & Female & Total & $95 \% \mathrm{Cl}$ & $p$ value \\
\hline \multicolumn{6}{|l|}{ Step 2 Physical measurements } \\
\hline Mean $\left(\mathrm{BMI}, \mathrm{kg} / \mathrm{m}^{2}\right)$ & 22.89 & 23.51 & 23.19 & $22.75-23.62$ & 0.162 \\
\hline Percentage who were overweight or obese (BMI $\left.\geq 25 \mathrm{~kg} / \mathrm{m}^{2}\right)$ & 18.8 & 32.4 & 25.3 & & 0.002 \\
\hline Percentage who are obese $\left(\mathrm{BMI} \geq 30 \mathrm{~kg} / \mathrm{m}^{2}\right)$ & 2.5 & 7.0 & 4.7 & & 0.034 \\
\hline Average waist circumference $(\mathrm{cm})$ & 84.52 & 86.99 & 85.70 & $84.54-86.86$ & 0.036 \\
\hline Mean (SBP, mmHg) & 127.1 & 125.9 & 126.49 & 124.4-128.5 & 0.575 \\
\hline Mean (DBP, mmHg) & 79.26 & 77.66 & 78.47 & $77.2-79.7$ & 0.214 \\
\hline Percentage with raised $\mathrm{BP}(\mathrm{SBP} \geq 140$ and/or $\mathrm{DBP} \geq 90 \mathrm{mmHg}$ ) & 44.6 & 35.4 & 40.0 & & 0.060 \\
\hline Percentage with raised $\mathrm{BP}(\mathrm{SBP} \geq 160$ and/or $\mathrm{DBP} \geq 100 \mathrm{mmHg})$ & 3.0 & 6.6 & 4.8 & & 0.207 \\
\hline Percentage with isolated systolic HPT (SBP $\geq 140$ and DBP $<90 \mathrm{mmHg}$ ) & 12.9 & 9.6 & 11.2 & & 0.300 \\
\hline
\end{tabular}

SBP:Systolicbloodpressure,DBP:Diastolicbloodpressure,BMI:Bodymassindex,Cl:Confidenceinterval,NCDs:Non-communicablediseases

had been to college or university, and even less $(0.75 \%)$ had a postgraduate degree. Participants had a largely uniform cultural structure, comprising $82.5 \%$ Akans and $12.25 \%$ from the Northern tribes collectively known as the Mole-Dagbani. With respect to occupation status, only $17.5 \%$ of study participants reported being either a student or volunteer worker. The rest were all involved in non-government employment $(61.5 \%)$ and government employment (15\%). A few were self-employed (6\%). Females were more likely to be self-employed while males were more likely to be government workers. Although all participants were old enough to marry, $24.75 \%$ had never been married before. Of those who had married before, $31.5 \%$ were currently together, $40 \%$ have been separated, and $3.75 \%$ were widowed.

A summary of the results from step one is given in Table 2. This shows that a lesser proportion of females was significantly more likely to be current smokers compared to males. Only $1.5 \%$ of all females were daily tobacco users while $22.4 \%$ of all males smoked daily. However, females were more likely to have a more sedentary lifestyle $(46.2 \%$ of females' vs. $29.7 \%$ of males) and eat less serving of fruits and vegetables (17.2\% vs. $36.1 \%)$ than males. The average number of servings of fruits and vegetables consumed per day was 1.59 (95\% CI; $1.41-$ 1.74 ) and 2.85 (95\% CI; 2.45-3.26), respectively. Males reported a higher mean number of fruits and vegetable servings than females and spent more time each day on physical activities compared to females.

Table 3 shows a summary of results from step 2 WHO STEPS approach to studying risk factors for NCDs. The average BMI of study participants was 23.19 (95\% CI; 22.75-23.62). Females (23.51) had a slightly higher BMI than males (22.89). In all, $25.3 \%$ and $4.7 \%$ of participants were overweight and 
obese respectively. Again, females were significantly more likely to be classified as overweight or obese as compared to their male counterparts (Pearson Chi-square $p<0.05$ ) and had a bigger mean waist circumference than males. The data show that $40 \%$ of all participants in this study had an elevated BP $(\geq 140 / 90 \mathrm{mmHg})$. There were more males $(44.6 \%)$ with elevated BP than females (35.4\%) and more males with severely elevated BP $(\geq 160 / 100 \mathrm{mmHg})$ than females. These findings were, however, not statistically significant. In all, the rate of isolated systolic HPT was $11.2 \%$ among the study population, $12.9 \%$ of males, and $9.6 \%$ among females.

\section{Risk factors for HPT}

Table 4 shows the odds of HPT (BP $\geq 140 / 90 \mathrm{mmHg}$ ) among study participants and corresponding 95\% CIs according to the demographic characteristics. Persons aged 65 years and over had the highest statistically significant odds of elevated BP among all study participants (odds ratio $[\mathrm{OR}]=5.33$, CI 2.31-12.27, $p=0.000$ ) followed by those aged $55-64$ years $(\mathrm{OR}=2.89$, CI $1.30-6.35, p=0.009)$ and $45-54$ years $(\mathrm{OR}=2.75$, CI 1.20-6.30, $p=0.017)$. Thus, the odds of developing HPT increased with advancing age. With respect to gender, the present data show that the odds of elevated $\mathrm{BP}$ in males are doubled compared to females. That is, males were twice as likely as females to develop HPT, all other things being equal. Concerning an individual's educational status, the odds of HPT follows a complicated pattern in which only those who completed secondary school (high school) were associated with significant odds of developing HPT $(\mathrm{OR}=0.365$, CI $0.14-0.98, p=0.046)$. Although not statistically significant, ewes had higher odds of developing HPT (OR = 2.67) compared with the other ethnic groups. The data also suggest that employment and marital status were not significant predictors of HPT among the study population.

Table 5 shows the odds of HPT (SBP $\geq 140$; DBP $\geq 90$ ) among study participants and corresponding 95\% CIs according to specific behavioral characteristics of participants such as tobacco use, alcohol use, and diet. Smoking was associated with significantly increased odds of elevated BP. Among all smokers, those who reported a habit of smoking daily were also at higher odds of having elevated BP.
The present data suggest that alcohol consumption may be associated with increased chances of having higher than the desired upper threshold of BP. Among all alcohol users, daily indulgers recorded the greatest odds $(\mathrm{OR}=5.28$, CI 1.09-25.41, $p=0.038)$ of elevated BP compared to those who took alcohol only rarely.

An individual's dietary habits concerning fruit and vegetable intake are thought to play a role in enhancing his/her likelihood of developing HPT. In this study, a habit of eating fewer fruits and vegetables every week was associated with significantly increased odds of having elevated BP as compared to individuals who eat more.

\section{DISCUSSION}

The present study examined the risk factors associated with HPT in the Dormaa Municipality. In all, $40 \%$ of participants had at least mild HPT (SBP $\geq 140$ and/or DBP $\geq 90 \mathrm{mmHg}$ ). This estimate is higher than both the year 2000 global estimate of $26.4 \%$ and the 2025 projected HPT prevalence estimate of $29.2 \%$ in the world's adult population (4). However, previous estimates from Ghana established the prevalence of HPT as high (i.e. >30\%) (7). Similarly, a study conducted by Bosu (11) has demonstrated that the epidemic of HPT in Ghana has persisted or increased. In 2007, the WHO estimated HPT prevalence of $25 \%$ in urban and $20 \%$ in rural populations. Either estimate is well below the $40 \%$ found in this study. Furthermore, the Women's Health Study of Accra reported a crude prevalence of $54.6 \%$ among 1303 women (23).

Globally, the prevalence of HPT is higher in males than in females (4). In the present study, $44.6 \%$ of males and $35.4 \%$ of females had at least mild HPT. However, in both cases, the worldwide estimates were lower than estimates from the present study. In conformity with our results, several studies in Africa and Ghana have shown some sex differences in the prevalence of HPT $(10,11,16,24)$.

This study found that the age-specific prevalence of HPT increased consistently with increasing age in all the population sub-groups, with a steeper increase in the age group of 55-64 years. A similar pattern has been reported in other studies $(7,24,25)$. For instance, a study by Agyemang et al. (7) revealed 
TABLE 4. Odds of HPT (SBP $\geq 140$; DBP $\geq 90$ ) among study participants and corresponding $95 \% \mathrm{Cls}$ according to the demographic characteristics

\begin{tabular}{|c|c|c|c|c|}
\hline \multirow[t]{2}{*}{ Parameter } & \multirow[t]{2}{*}{ Total } & \multicolumn{2}{|c|}{ Elevated BP } & \multirow[t]{2}{*}{$p$ value } \\
\hline & & OR & $95 \% \mathrm{Cl}$ & \\
\hline \multicolumn{5}{|l|}{ Age group } \\
\hline $25-34$ & $77(19.2)$ & & & \\
\hline $35-44$ & $84(21.0)$ & 1.377 & $0.59-3.22$ & 0.464 \\
\hline $45-54$ & $79(19.8)$ & 2.745 & $1.20-6.30$ & 0.017 \\
\hline $55-64$ & $81(20.2)$ & 2.875 & $1.30-6.35$ & 0.009 \\
\hline$\geq 65$ & $79(19.8)$ & 5.330 & $2.31-12.27$ & 0.000 \\
\hline \multicolumn{5}{|l|}{ Gender } \\
\hline Male & $202(50.5)$ & & & \\
\hline Female & $198(49.5)$ & 0.492 & 0.280 .86 & 0.012 \\
\hline Education & & & & 0.467 \\
\hline No formal school & $150(37.5)$ & & & \\
\hline Less than primary school & $15(3.8)$ & 0.973 & $0.27-3.50$ & 0.966 \\
\hline Completed prim school & $31(7.8)$ & 1.847 & $0.68-4.98$ & 0.226 \\
\hline JSS/Middle school & $129(32.2)$ & 0.881 & $0.48-1.61$ & 0.681 \\
\hline SHS/High school & $45(11.2)$ & 0.365 & $0.14-0.98$ & 0.046 \\
\hline College/University & $27(6.8)$ & 1.033 & $0.39-2.77$ & 0.948 \\
\hline Postgraduate degree & $2(0.5)$ & 0.645 & $0.02-16.99$ & 0.793 \\
\hline Ethnicity & & & & 0.352 \\
\hline Akan & $330(83.3)$ & & & \\
\hline $\mathrm{Ga}$ & $8(2.0)$ & 0.412 & $0.03-6.14$ & 0.520 \\
\hline Ewe & $9(2.3)$ & 2.668 & $0.49-14.54$ & 0.257 \\
\hline Mole Dagbani & $49(12.4)$ & 0.671 & $0.30-1.49$ & 0.329 \\
\hline Work status & & & & 0.839 \\
\hline Government employee & $58(14.5)$ & & & \\
\hline Non-Government employee & $246(61.7)$ & 1.175 & $0.65-2.14$ & 0.227 \\
\hline Self employed & $14(3.5)$ & 0.760 & $0.21-2.73$ & 0.745 \\
\hline Volunteer & $25(6.3)$ & 1.754 & $0.68-4.55$ & 0.199 \\
\hline Student & $44(11.0)$ & 1.900 & $0.85-4.24$ & 0.245 \\
\hline Marital status & & & & 0.979 \\
\hline Never married & $40(11.7)$ & & & \\
\hline Currently married & $126(36.8)$ & 0.818 & $0.35-1.90$ & 0.638 \\
\hline Separated & $160(46.8)$ & 0.822 & $0.369-1.83$ & 0.631 \\
\hline Widowed & $15(4.4)$ & 1.157 & $0.246-5.44$ & 0.853 \\
\hline
\end{tabular}

Cl: Confidence interval, OR: Odds ratio, BP: Blood pressure, HTTP: Hypertension SBP: Systolic blood pressure,

DBP: Diastolic blood pressure

that old age was independently associated with poorer BP control even though they had higher HPT awareness and treatment.

Furthermore, BMI in this study was significantly associated with SBP and DBP, which was consistent with the WHO STEPS study in Asian and African countries (26). According to the researchers, the mean BP levels increased with increasing BMI, and the risk of HPT was higher among individuals who were overweight and obese (BMI $\geq 25 \mathrm{~kg} /$ $\mathrm{m}^{2}$ ). On the other hand, the epidemiologic feature of malnourished populations where HPT is associated with low BMI was not found in this present study. On the contrary, Tesfaye et al. (26) found 
TABLE 5. Odds of HPT (SBP $\geq 140$; DBP $\geq 90$ ) according to the behavioral characteristics

\begin{tabular}{lccc}
\hline Parameter & \multicolumn{2}{c}{ Elevated BP } & p value \\
\cline { 2 - 3 } & OR & $95 \% \mathrm{Cl}$ & \\
\hline Tobacco status & & & \\
smokers & 2.66 & $1.41-5.04$ & 0.003 \\
Non-smokers & 1 & & \\
$\quad$ Tobacco frequency & & & \\
Daily & 1.23 & $0.52-2.48$ & 0.109 \\
$\quad$ Non-daily & 1 & & \\
Alcohol status & & & \\
Ever consumed & 1.59 & $0.97-2.61$ & 0.069 \\
Never consumed & 1 & & \\
Alcohol frequency & & & \\
Daily & 5.28 & $1.09-25.41$ & 0.038 \\
5-6 days/week & 0.45 & $0.05-4.06$ & 0.478 \\
3-4 days/week & 1.36 & $0.30-6.08$ & 0.690 \\
1-2 days/week & 1.44 & $0.42-4.98$ & 0.565 \\
1-3 days/month & 1.50 & $0.54-4.18$ & 0.438 \\
Less than once a month & 1 & & \\
Diet & & & \\
$\quad$ Fruit and vegetable & & & \\
servings/week & & & \\
$\quad>5$ & 0.321 & $0.15-0.67$ & 0.003 \\
$<5$ & 1 & & \\
\hline
\end{tabular}

Cl: Confidence interval, OR: Odds ratio, BP: Blood pressure, SBP: Systolic blood pressure, DBP: Diastolic blood pressure

that HPT often exists in a background of undernutrition in developing countries where extremely low or high BMI levels may both be associated with increased risk of HPT. However, dietary salt intake level which may be a confounding factor was not measured in this study.

Furthermore, the study found about $22 \%$ prevalence rate of current smokers which is higher than studies conducted with a similar methodology in sub-Saharan Africa (Eritrea 15.7\%), even though it is lower than prevalence estimates in other developing countries, such as Singapore with $26.5 \%$ or Kuwait with $34.4 \%(25,27)$. The findings were, however, similar to findings from both of these countries in terms of sex differences, in which smoking prevalence is higher in males than females. Considering the autonomy of men in the family, the outcome of this study should also raise concerns about the implications of passive smoking on others, particularly children. On the other hand, a similar study conducted in Indonesia (28) reported that about $54 \%$ of men and $27.6 \%$ of the general population were smoking on a daily basis. More than one-third of the population in this study had a low level of physical activity, which was higher among women and higher age groups. This finding is consistent with other studies in the Middle East $(29,30)$. Furthermore, it is documented that individuals having higher activity also had a lower BMI (31-33).

The prevalence of overweight and obesity was $25.3 \%$. This estimate lies in a range reported by studies in some developing countries. Similar to our findings, other studies have also shown that obesity is less common in early adulthood and advances faster among women (29). The BMI alone has been found to be a strong independent predictor of HPT (5). A stable linear relationship between adiposity and BP has been reported, independent of age and body-fat distribution across developed and developing countries (25).

Mean daily servings of both fruit and vegetables in this study are reasonably similar to those in some other countries. Fruit and vegetable consumption has always been an important scientific health recommendation while other studies showed most persons ate two or fewer servings of fruits or vegetables daily. This to some extent highlights how low premium is placed on the intake of fruit and vegetables (34).

\section{CONCLUSIONS}

Using the highly rated and standardized the WHO STEPwise instrument, we estimated the prevalence of HPT in the Dormaa Municipality, in the BrongAhafo region of Ghana. The overall prevalence of HPT (SBP $\geq 140$ and/or DBP $\geq 90 \mathrm{mmHg}$ ) was $40 \%$, and the prevalence of isolated systolic HPT was $11.2 \%$ among the study population. Advancing age, smoking, and low physical activity among others were identified as the major risk factors for HPT among the population.

The prevalence rate of daily smoking was $12 \%$ with variations among age and sex. A high prevalence of low fruit and low vegetable intake was also observed. Percentage who ate $\geq 5$ combined servings of fruit and vegetables per day was only $26.8 \%$. Alcohol consumption was $39.6 \%$. The prevalence of obesity was low at $4.7 \%$. Combined risk factor analysis 
showed that $2.8 \%$ of participants were in the lowrisk group (up to $5.1 \%$ among men and $0.5 \%$ among women). In addition, $21.5 \%$ of participants were at high risk for developing HPT. The results of the present study provide useful data on HPT prevalence and associated risk factors in Dormaa and the Brong-Ahafo region.

\section{CONFLICT OF INTEREST}

The authors declare that they have no competing interest.

\section{REFERENCES}

1. World Health Organization. The World Health Report 2002: Reducing Risks, Promoting Healthy Life. Geneva: World Health Organization; 2002. Available from: https://www.books.google. $\mathrm{com} /$ books?hl=en\&lr=\&id=epuQi1PtY_cC\&oi=fnd\&pg=PR9\&d$q=+W H O+(2002)+$ The+world +health+report+2002:+reducing+risks, +promoting +healthy+life.+Geneva:+World+Health+Organization.\&ots=N3E3bRDjPp\&sig=diq0xUIVwYfhExmVmJKrhSi-jRw. [Last cited on 2017 Sep 14].

2. Riley L, Guthold R, Cowan M, Savin S, Bhatti L, Armstrong T, et al. The world health organization STEPwise approach to noncommunicable disease risk-factor surveillance: Methods, challenges, and opportunities. Am J Public Health 2016;106(1):74-8. https://doi.org/10.2105/AJPH.2015.302962.

3. Zein ZA, Assefa M. Blood-pressure levels and hypertension in rural Ethiopian communities. Ethiop Med J 1986;24(4):169-78.

4. Kearney PM, Whelton M, Reynolds K, Muntner P, Whelton PK, He J, et al. Global burden of hypertension: Analysis of worldwide data. Lancet 2005;365(9455):217-23.

\section{https://doi.org/10.1016/S0140-6736(05)70151-3.}

5. Forman JP, Stampfer MJ, Curhan GC. Diet and lifestyle risk factors associated with incident hypertension in women. JAMA 2009;302(4):401-11.

https://doi.org/10.1001/jama.2009.1060.

6. Colbourne MJ, Edington GM, Hughes MH, Ward-Brew A. A medical survey in a gold coast village. Trans R Soc Trop Med Hyg 1950;44(3):271-90.

https://doi.org/10.1016/0035-9203(50)90055-1.

7. Agyemang $\mathrm{C}$, Bruijnzeels MA, Owusu-Dabo E. Factors associated with hypertension awareness, treatment, and control in Ghana, West Africa. J Hum Hypertens 2006;20(1):67-71. https://doi.org/10.1038/sj.jhh.1001923.

8. Addo J, Smeeth L, Leon DA. Prevalence, detection, management, and control of hypertension in Ghanaian civil servants. Ethn Dis 2008;18(4):505-11.

9. Ghana Health Service. Centre for Health Information Management: Outpatient Morbidity in Health Facilities. Accra, Ghana: Ghana Health Service; 2008

10. Addo J, Agyemang C, Smeeth L, de-Graft Aikins A, Edusei AK, Ogedegbe $\mathrm{O}$, et al. A review of population-based studies on hypertension in Ghana. Ghana Med J 2012;46(2):4-11.

11. Bosu WK. Epidemic of hypertension in Ghana: A systematic review. BMC Public Health 2010;10(1):418. Available from: https://www.bmcpublichealth.biomedcentral.com/articles/10.1186/1471-2458-10-418. [Last cited on 2017 Sep 10].

https://doi.org/10.1186/1471-2458-10-418.

12. Ohene Buabeng K, Matowe L, Plange-Rhule J. Unaffordable drug prices:
The major cause of non-compliance with hypertension medication in Ghana. J Pharm Pharm Sci 2004;7(3):350-2.

13. de-Graft Aikins A. Ghana's neglected chronic disease epidemic: A developmental challenge. Ghana Med J 2007;41(4):154-9.

14. Addo J, Amoah AG, Koram KA. The changing patterns of hypertension in Ghana: A study of four rural communities in the Ga district. Ethn Dis 2006;16(4):894-9.

15. Agyemang $C$. Rural and urban differences in blood pressure and hypertension in Ghana, West Africa. Public Health 2006;120(6):525-33.

https://doi.org/10.1016/j.puhe.2006.02.002.

16. Amoah AG. Hypertension in Ghana: A cross-sectional community prevalence study in greater Accra. Ethn Dis 2003;13(3):310-15. Available from: http://www.europepmc.org/abstract/med/12894954. [Last cited on 2017 Sep 10].

17. Cappuccio FP, Micah FB, Emmett L, Kerry SM, Antwi S, Martin-Peprah R, et al. Prevalence, detection, management, and control of hypertension in Ashanti, West Africa. Hypertension 2004;43(5):1017-22. https://doi.org/10.1161/01.HYP.0000126176.03319.d8.

18. Ghana Statistical Service. National Population and Housing Census, Year 2010 Report; 2012.

19. Israel GD. Determining Sample Size. University of Florida Cooperative Extension Service, Institute of Food and Agriculture Sciences, EDIS; 1992. Available from: http://www.soc.uoc.gr/socmedia/papageo/metaptyxiakoi/ sample_size/samplesize1.pdf. [Last cited on 2015 Jun 8].

20. Utts JM, Heckard RF. Mind on Statistics. Cengage Learning; 2011 Available from: https:/www.books.google.co.uk/books?hl=en\&lr=\&id=IV4IAAAAQBAJ\&oi=fnd\&pg=PR6\&dq=mind+on+statistics\&ots=iYcvccpypf\&sig=WCDrlr13xevQVbPgHwX9fMAWdVg. [Last cited on 2016 Jul 24].

21. World Health Organization, ControlRfor IT.WHOReportonthe Global Tobacco Epidemic, 2008: The MPOWER Package. World Health Organization; 2008 Available from: https://www.books.google.com/books?hl=en\&lr=\&id=y6YsDwAAQBAJ\&oi=fnd\&pg=PA7\&dq=WHO+(2008b)+World+Health+Organization:+WHO+STEPS+Surveillance+Manual.+Geneva:+WHO.\&ots $=Y 5$ RB1FJnl_\&sig=WOwa1TCrZUU3eqiqg8iunEJmMGg. [Last cited on 2017 Sep 14].

22. Guthold R, Louazani SA, Riley LM, Cowan MJ, Bovet P, Damasceno A et al. Physical activity in 22 African countries: Results from the world health organization STEPwise approach to chronic disease risk factor surveillance. Am J Prev Med 2011;41(1):52-60.

https://doi.org/10.1016/j.amepre.2011.03.008.

23. Duda RB, Kim MP, Darko R, Adanu RM, Seffah J, Anarfi JK, et al. Results of the women's health study of accra: Assessment of blood pressure in urban women. Int J Cardiol 2007;117(1):115-22.

https://doi.org/10.1016/j.jijcard.2006.05.004.

24. Mufunda J, Mebrahtu G, Usman A, Nyarango P, Kosia A, Ghebrat $Y$, et al. The prevalence of hypertension and its relationship with obesity: Results from a national blood pressure survey in Eritrea. J Hum Hypertens 2006;20(1):59-65

https://doi.org/10.1038/sj.jhh.1001924.

25. Bovet P, Ross AG, Gervasoni JP, Mkamba M, Mtasiwa DM, Lengeler C, et al. Distribution of blood pressure, body mass index and smoking habits in the urban population of Dar Es Salaam, Tanzania, and associations with socioeconomic status. Int J Epidemiol 2002;31(1):240-7.

https://doi.org/10.1093/ije/31.1.240.

26. Tesfaye F, Nawi NG, Van Minh H, Byass P, Berhane Y, Bonita R, et al. Association between body mass index and blood pressure across three populations in Africa and Asia. J Hum Hypertens 2007;21(1):28-37.

https://doi.org/10.1038/sj.jhh.1002104

27. Memon A, Moody PM, Sugathan TN, el-Gerges N, al-Bustan M, al-Shatti A, et al. Epidemiology of smoking among Kuwaiti adults: Prevalence, characteristics, and attitudes. Bull World Health Organ 2000;78(11):1306-15. 
28. $\mathrm{Ng} \mathrm{N}$, Stenlund $\mathrm{H}$, Bonita R, Hakimi M, Wall S, Weinehall L, et al. Preventable risk factors for noncommunicable diseases in rural Indonesia: Prevalence study using WHO STEPS approach. Bull World Health Organ 2006;84(4):305-13.

https://doi.org/10.2471/BLT.05.023721.

29. Seyffarshad M, Kousha A, Pourdowlati S, Karamouz M, Farahbakhsh M, Hakimi S, et al. Cardiac risk factor analysis in East Azerbaijan, Iran. Cardiology 2007;3(1):1-4. Available from: http://www.docsdrive.com/pdfs/ medwelljournals/tcard/2007/1-4.pdf. [Last cited on 2017 Sep 14].

30. Sadeghi-Bazargani H, Jafarzadeh H, Fallah M, Hekmat S, Bashiri J, Hosseingolizadeh $\mathrm{Gh}$, et al. Risk factor investigation for cardiovascular health through WHO STEPS approach in Ardabil, Iran. Vasc Health Risk Manag 2011;7:417-24.

31. Sibai AM, Hwalla N, Adra N, Rahal B. Prevalence and covariates of obesity in Lebanon: Findings from the first epidemiological study. Obes Res 2003;11(11):1353-61. https://doi.org/10.1038/oby.2003.183.

32. Slattery ML, Sweeney C, Edwards S, Herrick J, Murtaugh M, Baumgartner K, et al. Physical activity patterns and obesity in hispanic and non-hispanic white women. Med Sci Sports Exerc 2006;38(1):33-41.

https://doi.org/10.1249/01.mss.0000183202.09681.2a.

33. Kelishadi R, Ardalan G, Gheiratmand R, Gouya MM, Razaghi EM, Delavari A, et al. Association of physical activity and dietary behaviours in relation to the body mass index in a national sample of Iranian children and adolescents: CASPIAN study. Bull World Health Organ 2007;85(1):19-26. https://doi.org/10.2471/BLT.06.030783.

34. American Heart Association Nutrition Committee, Lichtenstein $\mathrm{AH}$ Appel LJ, Brands M, Carnethon M, Daniels S, et al. Diet and lifestyle recommendations revision 2006: A scientific statement from the American heart association nutrition committee. Circulation 2006;114:82-96.

https://doi.org/10.1161/CIRCULATIONAHA.106.176158. 